\title{
A new methodology of constructing products using Additive Manufacturing Technology: Case study of a push button
}

\author{
Konstantinos Bailas and Paraskevas Papanikos \\ Department of Product and Systems Design Engineering, University of the Aegean, \\ Ermoupolis, Syros, Greece.
}

\begin{abstract}
The effective construction of innovative and customized products using Additive Manufacturing Technology remains a challenging task when dealing with mass production in industry. This paper describes a new methodology for solving various problems of constructing a product using Additive Manufacturing technology. The objective is to minimize the number of parts of the final product by embedding those parts to the main geometry while simultaneously increasing the lifecycle of the product. This can be achieved by integrating one or more parts to the main structure of the product with the proper use of a parametric CAD system that generates parts with parameterization and constraints. The developed methodology has been applied to the manufacturing of a push button as an integrated product consisting only of one part. Finite element simulation and mechanical testing was used to verify the approach based on design requirements related to fatigue strength and distance to stroke. The results demonstrate the effectiveness of the proposed approach.
\end{abstract}

Keywords: Additive Manufacturing Technology, Product Lifecycle, Design Intent, Finite Element Analysis, push button

\section{Introduction}

Additive manufacturing (AM), also referred to as 3D printing [1], is a technology that draws attention of academics and manufacturing industries over the last 20 years and has been dynamically entered the field of low volume production in industry [2,3]. AM contribution to the manufacturing industries is believed to be revolutionary [4] and recent applications of this technology as the manufacturing of metallic components, show that this revolution has become more realistic than ever [5]. One of the most important advantages of AM technology in industry is the ability to fabricate complex geometries, customized, sustainable and flexible products that are impossible to build with traditional methods such as tools or molds, during the manufacturing process [6]. The processes and a wide variety of materials that AM uses can build complex geometries that in many cases, reduce the assembly work needed to accomplish a final product and can be further optimized according to functionality with no need of restrictions set from production technology or supply chain constraints [3]. However, the capabilities of AM 
in industry have a numerous of limitation that need to be consider when dealing with mass production. Specifically, low production speed compared to conventional production methods and many individual moving parts that make up a product, makes the integration of AM technology into mass production a difficult issue [2,3]. Nevertheless, design for manufacturing and assembly (DFM) gave the designers the opportunity to solve serious problems in manufacturing using AM and many companies are now having successful production lines, such as Siemens, Boeing and others with customized products [7]. Products made of AM processes are models from various CAD systems [8]. Each model contains information such as geometric properties and relations between edges, faces, vertices and sub-parts that determines its design intent. A shape of a model determines most of the time its function and is important for controlling the effectiveness of above parameters during the Finite Element Analysis (FEA). This is proven to be crucial for estimating the lifecycle of the product [9]. The reduction of the number of parts that consist a final product without affecting its function and durability can reduce the production time since no extra time is required for its assembly [8]. In this paper, a methodology for the reduction of the number of parts is developed and applied by embedding a push-button to the main geometry of a product during the design process. A push-button is a simple switch mechanism for controlling some aspect of a machine and having rectilinearly-movable operating part or parts adapted for pushing or pulling in one direction only [10].

\section{Design Intent}

Using a state of the art parametric CAD system, three different products were created, i.e., Specimens A, B and C (Fig. 1). Each specimen simulates a push button and consists of three different geometries, Geometry A (Chassis), Geometry B (Two Ribs) and Geometry C (Push Button) that were all embedded into one solid (Fig. 2).
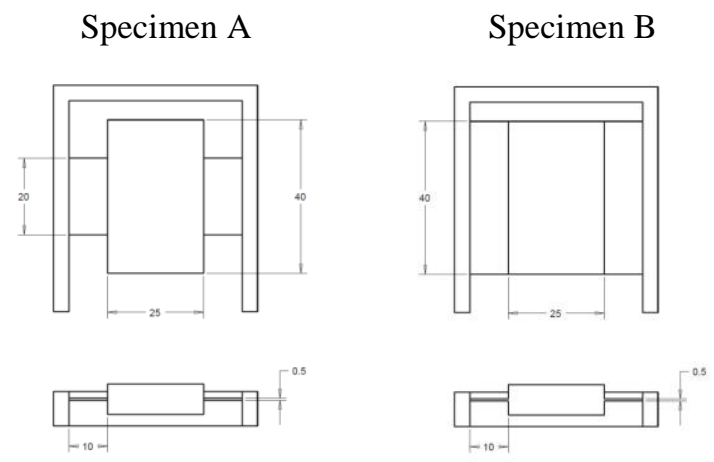

\section{Specimen C}

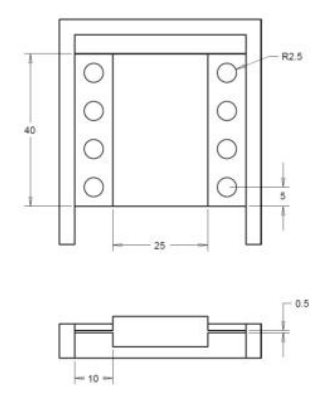

Fig. 1. Specimens geometry. 
Design intent played an important role during the design process of those specimens and included all the necessary product information, such as parameters and constrains to easy manipulate the geometry of each specimen. These parameters were the "Length", "Width" and "Thickness" for each rib of Geometry B (Fig. 3), the value of radius for each hole for Specimen $\mathrm{C}$ and the definition of constant parameters for Geometry C (Fig.1).

Design intent also helped to control the effectiveness of those specific parameters during the Finite Element Analysis (FEA) in a targeting manner without affecting, e.g. geometries $\mathrm{A}$ and $\mathrm{C}$. It should be noted that rib thickness was set to $0.5 \mathrm{~mm}$ to be within the tolerances of structural stability of the additive machines, which were used for manufacturing the prototypes.

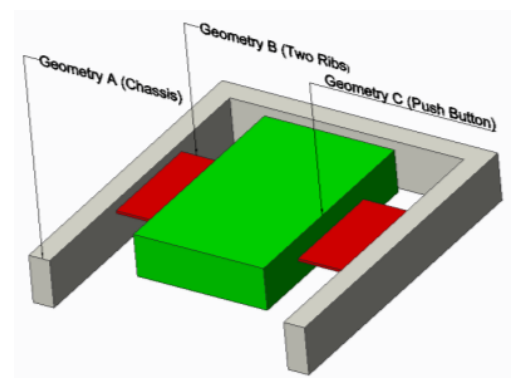

Fig. 2. Geometries that consist the push button.

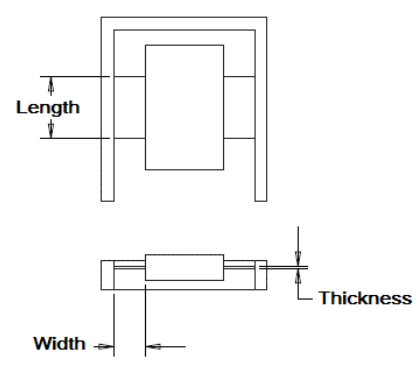

Fig. 3. Parameters of geometry B.

\section{Analysis and Optimization}

Using Creo Simulate platform, mechanical analyses of specimens A, B and C were carried out to evaluate the relationship between equivalent stress (von Mises) and displacement for each push button (Table 1). The applied force at the top plane of each push button was set to $5 \mathrm{~N}$, a common force value for triggering a push button (Fig. 4) [10]. We use three different materials that are widely used in additive manufacturing 
machines. These are ABS with Young's Modulus $2 \mathrm{GPa}$ and density $1100 \mathrm{~kg} / \mathrm{m}^{3}$, PLA with Young's modulus $2.1 \mathrm{GPa}$ and density $1250 \mathrm{~kg} / \mathrm{m}^{3}$ and PA6 with Polycarbonate (PC) blend material with Young's modulus $0.48 \mathrm{GPa}$ and density $350 \mathrm{~kg} / \mathrm{m}^{3}$. The values of the Young's moduli were measured from simple three-point bend tests of flat specimens made from the three materials and corresponding additive manufacturing techniques. This was important for the correct analyses using CreoSimulate platform and for the comparison between the simulation and testing results related to the mechanical behavior of the push buttons that follows in another section of this paper. Figs. 5 and 6 show the stress distribution and the deformation of specimen $\mathrm{C}$. The maximum displacement value for each of the above material specimens (Tables 1,2,3) determines which geometry is appropriate to activate a button at a force of $5 \mathrm{~N}$.

Table 1. Analyses results for ABS, using Creo Simulate platform.

\begin{tabular}{lll}
\hline Specimen & $\begin{array}{l}\text { Maximum displace- } \\
\text { ment }(\mathrm{mm})\end{array}$ & Maximum stress (MPa) \\
\hline A & 0.468 & 14.4 \\
B & 0.231 & 6.5 \\
C & 0.252 & 8.0 \\
\hline
\end{tabular}

Table 2. Analyses results for PLA, using Creo Simulate platform.

\begin{tabular}{lll}
\hline Specimen & $\begin{array}{l}\text { Maximum displace- } \\
\text { ment }(\mathrm{mm})\end{array}$ & Maximum stress $(\mathrm{MPa})$ \\
\hline $\mathrm{A}$ & 0.445 & 14.4 \\
$\mathrm{~B}$ & 0.220 & 6.5 \\
$\mathrm{C}$ & 0.263 & 8.0 \\
\hline
\end{tabular}

Table 3. Analyses results for PA6-PC, using Creo Simulate platform.

\begin{tabular}{lll}
\hline Specimen & $\begin{array}{l}\text { Maximum displace- } \\
\text { ment }(\mathrm{mm})\end{array}$ & Maximum stress $(\mathrm{MPa})$ \\
\hline $\mathrm{A}$ & 1.949 & 14.4 \\
$\mathrm{~B}$ & 0.961 & 6.5 \\
$\mathrm{C}$ & 1.050 & 8.0 \\
\hline
\end{tabular}




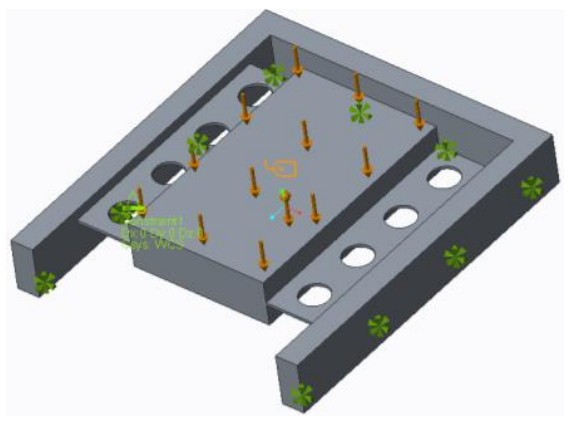

Fig. 4. Applied force on specimen C.

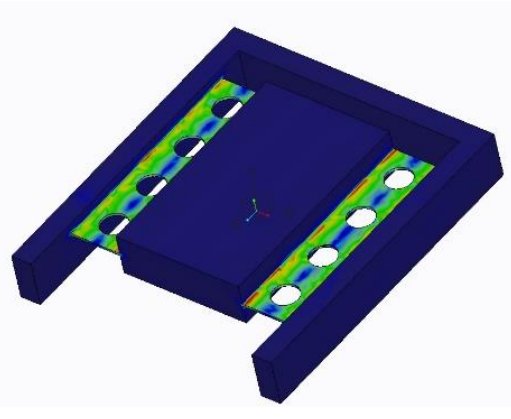

Fig. 5. Stress distribution of specimen C.

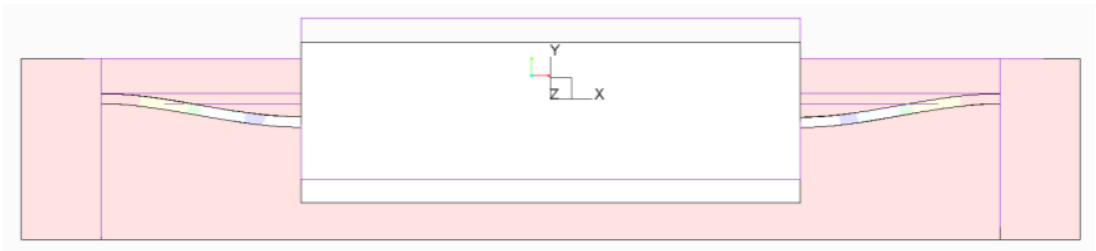

Fig. 6. Maximum displacement for specimen C.

The results of the analyses for ABS material for each of three specimens showed that the maximum stress developed in specimens $\mathrm{B}$ and $\mathrm{C}$ was lower than the minimum reported fatigue strength of the material, which is $11 \mathrm{MPa}$ [11]. For specimen A the maximum stress is larger than the lower fatigue strength but well within the allowable range of $11-24 \mathrm{MPa}$ [11]. Since the maximum stress value of specimens B and C are much lower than the fatigue strength, we can conclude that their geometry can be further optimized. The results of the analyses for PLA material for each of the three specimens showed that the maximum stress developed in all specimens was much lower than the minimum fatigue strength of the material, which is $45 \mathrm{MPa}$ [12]. This means that their geometry can be change much more drastically than the geometry of ABS specimens. On the contrary the results of the analyses for PA6-PC material for each of three specimens showed that the maximum stress developed in specimens A, B and C was above the minimum fatigue strength of the material, which is $5 \mathrm{MPa}$ [12], meaning a short life cycle of a product. The analyses for all materials (ABS, PLA, PA6-PC) also demonstrated that geometry B (ribs) and its parameters (Figs. 2 and 3) strongly influences the maximum stress values, whereas virtually no influence was found for the other two parts.

Considering the effectiveness of Geometry B (ribs) to the mechanical behavior of each specimen an optimization study was carried out. The design limits considered related to specific values for the maximum displacement $(=0.5 \mathrm{~mm})$ and depend on the material fatigue strength, i.e. $11 \mathrm{MPa}, 45 \mathrm{MPa}$ and $5 \mathrm{MPa}$, respectively. The design parameters were the width and thickness values for all specimens and the radius value for 
specimen $\mathrm{C}$. Width was set to a range of 10 to $20 \mathrm{~mm}$ due to constraints we have during the design process in relation to other neighboring objects, such as electronic boards, batteries, etc. The thickness of each rib was set to a range of 0.5 to $1 \mathrm{~mm}$, which helps staying within the tolerance of structural stability of the additive manufacturing machines. Radius was set to a range of 5 to $8 \mathrm{~mm}$, a value indicating how dense the netting to be created on the ribs of specimen $\mathrm{C}$ would be.

The value of the maximum displacement for push buttons is also called "Displacement to Stroke" and means the displacement of the button, from its initial position until it reaches the activation point, and its value varies according the technical specifications of its button [13]. The results of the optimization study for each of three materials (Tables $4,5,6$ ) showed that we had the ability to control the "Displacement to Stroke" value of each button under certain design limits without exceeding the fatigue strength for a specific material while maintained the geometry at the desired limits. It was also noticed that mechanical optimization analyses helped to find and predict an optimum geometry that can be functional when integrating it into a final solid during additive manufacturing process.

Table 4. Optimization study for ABS specimens.

\begin{tabular}{llll}
\hline Specimen & $\begin{array}{l}\text { Optimum } \\
\text { width }(\mathrm{mm})\end{array}$ & $\begin{array}{l}\text { Optimum } \\
\text { height }(\mathrm{mm})\end{array}$ & $\begin{array}{l}\text { Optimum } \\
\text { radius }(\mathrm{mm})\end{array}$ \\
\hline $\mathrm{A}$ & 13.85 & 0.68 & - \\
$\mathrm{B}$ & 13.07 & 0.50 & - \\
$\mathrm{C}$ & 12.26 & 0.50 & 5.67 \\
\hline
\end{tabular}

Table 5. Optimization study for PLA specimens.

\begin{tabular}{llll}
\hline Specimen & $\begin{array}{l}\text { Optimum } \\
\text { width }(\mathrm{mm})\end{array}$ & $\begin{array}{l}\text { Optimum } \\
\text { height }(\mathrm{mm})\end{array}$ & $\begin{array}{l}\text { Optimum } \\
\text { radius }(\mathrm{mm})\end{array}$ \\
\hline A & 10.1 & 0.50 & - \\
B & 10.2 & 0.50 & - \\
C & 10.1 & 0.50 & 8.0 \\
\hline
\end{tabular}

Table 6. Optimization study for PA6-PC specimens.

\begin{tabular}{llll}
\hline Specimen & $\begin{array}{l}\text { Optimum } \\
\text { width }(\mathrm{mm})\end{array}$ & $\begin{array}{l}\text { Optimum } \\
\text { height }(\mathrm{mm})\end{array}$ & $\begin{array}{l}\text { Optimum } \\
\text { radius }(\mathrm{mm})\end{array}$ \\
\hline $\mathrm{A}$ & 10 & 0.92 & - \\
$\mathrm{B}$ & 10 & 0.57 & - \\
$\mathrm{C}$ & 10 & 0.64 & 5.12 \\
\hline
\end{tabular}


Due to the large fatigue strength of PLA, and the manufacturing related limit of minimum thickness of $0.5 \mathrm{~mm}$, the optimized geometry for specimens A and B relates to the minimum values of thickness and width. In this case, the maximum stress obtained is only $15 \mathrm{MPa}$, which is much smaller than the fatigue strength, meaning that for the PLA material and the optimized geometry the life cycle of the product is almost infinite. For the PA6-PC material, due to its low strength, the optimized geometry corresponds to high thickness values (e.g. from 0.57 to $0.92 \mathrm{~mm}$ ).

\section{$4 \quad$ Experimental investigation}

All experiments were carried out at the Integrated Industrial Design Lab (INDEL) of the Aegean University at the Department of Product and Systems Design Engineering. We used two different technologies of Additive manufacturing machines and three kinds of materials to produce a total of nine physical products for our experiment. Fused Deposition Modelling (FDM) Technology was used to produce three ABS and PLA specimens using Dimension STRATASYS and Davinci PRO XYZPrinting model machine, respectively. Using Selective Heat Sintering (SHS) technology with Blueprinter M02 model machine, we produced three more Polyamide 6 (PA6)- Polycarbonate(PC) specimen prototypes needed for our experiment. A mechanical testing machine, SHIMADZU AGS-X Series was used to measure the applied force in relation to displacement of each of nine products (Fig. 7). Displacement was applied at a speed of $2 \mathrm{~mm} / \mathrm{sec}$ and the corresponding force was measured up to a maximum force of $6 \mathrm{~N}$.

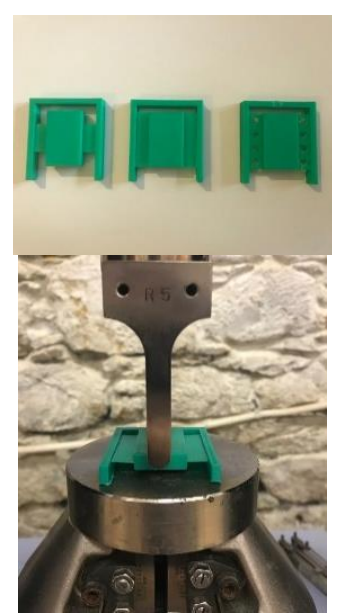

ABS

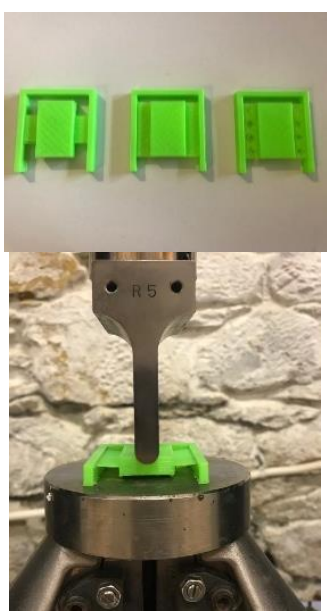

PLA

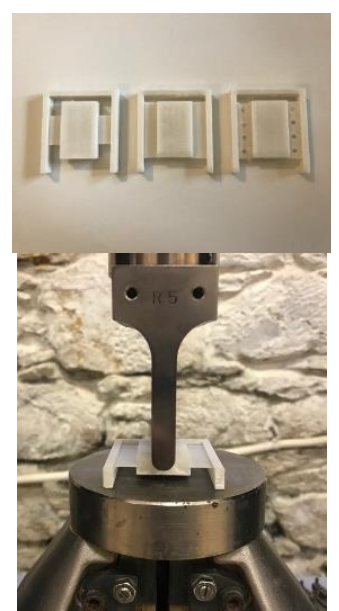

PA6-PC

Fig. 7. Specimens and testing procedure.

The above nine specimens were also modelled using Creo Simulate platform to compare the experimental and predicted mechanical behavior. Apart from the geometrical features, the inputs to the models were the mechanical and physical material properties described above. 
The results are presented in Fig. 8 in the form of force-displacement curves. All simulation results are straight lines as the materials behavior was assumed perfectly linear-elastic for the small loads considered (up to $6 \mathrm{~N}$ ). The experimental results showed similar behavior with very small deviation from a straight line. Careful examination showed that this is due to small slips (e.g. chassis) during testing and not due to non-linear material behavior. This was also verified by measuring residual deformations of the specimens after load removal, which were found to be less than 0.005 $\mathrm{mm}$.

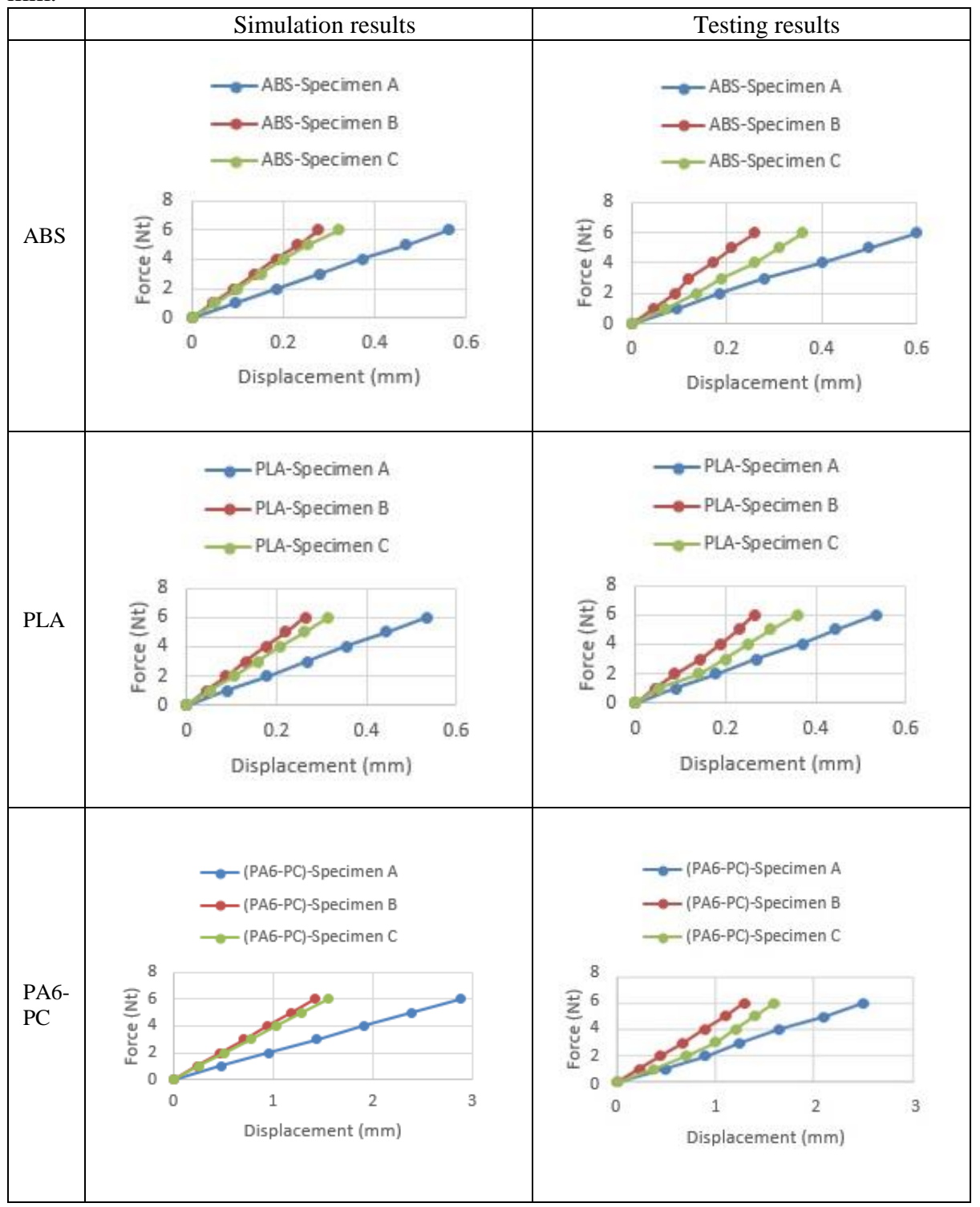


Fig. 8. Comparison between simulation and testing results.

Fig. 8 shows that for all cases examined, specimen B shows larger stiffness followed by $\mathrm{C}$ and $\mathrm{A}$. As expected from the stiffness of the materials, specimens made from PLA showed the larger stiffness, followed closely by ABS, both having a stiffness of about $20 \mathrm{~N} / \mathrm{mm}$. Push buttons made of PA6-PC showed very small stiffness of about $4 \mathrm{~N} / \mathrm{mm}$. Testing results are very close to simulation results with maximum deviation less than $5 \%$ for the stiff materials (ABS and PLA) and larger for the soft material (PA6-PC) up to $15 \%$.

\section{Conclusions}

Using AM technology, we can produce industrial products made up of individual parts in a small -scale industry. In this paper, it has been demonstrated that if some of these parts are incorporated into the main geometry of a product, during the design process, by using a CAD system and by introducing appropriately the concept of design intent, we have the possibility to produce equally functional products where embedded moving parts perform the same function and exhibit the same or even greater durability than being separate parts. This has the effect of reducing the production time since fewer sub-products of an assembly will have to be produced using less manufacturing technologies, while at the same time removing the cost of the extra moving parts, thereby significantly reducing its total production cost. In the example of the push button using design intent, all the information and constraints to achieve the integration of geometry were incorporated into a CAD model. It has been shown that those information's significantly influences the production of an assembly that used AM technology to be manufacture. In this way, the following were achieved:

No moving parts (e.g. chassis) can be designed so they are not affected during the operation of the moving parts. This is important because it was demonstrated that we can control which geometry will or may not be affected by the moving parts incorporated into it

It has been shown that we can evaluate, using FEA which material (used by AM technology) is the most suitable and meets the requirements of the built-in geometry.

It has been demonstrated that we can estimate the optimal geometry to achieve a long product life cycle of a product before its production, considering the fatigue strength.

It has been shown that the use of netting and the density of it, affects the function of an integrated geometry, leading to lower mass and cost, without altering the function of a product. 


\section{References}

1. Lipson, H., Kurman, M., : The new world of 3D printing, $1^{\text {st }}$ edn. John Wiley\&Sons, Inc, Indianapolis (2013).

2. Wei Gao, Yunbo Zhang, Devarajan Ramanujan, Karthik Ramani, Yong Chen, Christopher B., Williams , Charlie, C.L., Wang, Yung, C., Shin , Song Zhang, Pablo, D., Zavattieri.: The status, challenges, and future of additive manufacturing in Engineering. Computer-Aided Design 69, 65-89 (2015), doi:10.1016/j.cad.2015.04.001.

3. Christian, W., Robin, K., FrankT.P. : Economic implications of 3D printing: Market structure models in light of additive manufacturing revisited, ProductionEconomics164, 43-56 (2015), doi:10.1016/j/ijpe.2015.02.020.

4. P.W. Liua, b, 1, Y.Z. Jic, 1, Z. Wangb, C.L. Qiud, A.A. Antonysamye, L.-Q. Chenc, X.Y. Cuia, , , L. Chenb.: Investigation on evolution mechanisms of sitespecific grain structures during metal additive manufacturing. In: Journal of Materials Processing Technology (2018), doi:10.1016/j.jmatprotec.2018.02.042.

5. Gustavo, T., Elwany, A.: A Review on Process Monitoring and Control in MetalBased Additive Manufacturing. In: J. Manuf. Sci. Eng, (2014), doi:10.1115/1.4028540.

6. Rodrigue, H., Rivette, M.: An assembly - Level Design for Additive Manufacturing Methodology. Hal. Archives-ouvertes (2015), doi:10.1007/978-2-8178-0169-8.

7. Gibson, I., Rosen, D., Stucker, B.: Design for Additive Manufacturing. Additive manufacturing Technologies, 399-435 (2015), doi:10.1007/978-1-4939-2113-3_17.

8. Nannan, GUO., Ming, C. L.: Additive manufacturing: technology, applications and research needs. In: Higher Education Press and Springer-Verlag Berlin Heidelberg (2013), doi:10.1007/s11465-013-0248-8.

9. Ming, Li., Frank, C, Langbein., R. Martin.: Detecting design intent in approximate CAD models using symmetry. Computer-Aided Design 42, 183_201 (2010), doi:10.1016/j.cad.2009.10.001.

10. Doerrer, C., Werthschuetzky, R.: Simulating Push-Buttons Using a Haptic Display: Requirements on Force Resolution and Force-Displacement Curve. ResearchGate (2002).

11. Kunwoo, L.: Principles of Cad/Cam/Cae Systems. $1^{\text {st }}$ edn. Addison Wesley Longman Inc. (1999).

12. Jerez-Mesa, R., Travieso-Rodriguez, J.A., Liuma-Fuentes, J., Gomez-Gras, G., Puig, D.: Fatigue lifespan study of PLA parts obtained by additive manufacturing. Procedia Manufacturing 13, 872-879 (2017), doi:10.1016/j.promfg.2017.09.146.

13. Malliaros, I.: An approach to identify the appropriate design requirements and specifications to define the target percept of an in-car interface: Case of Non-Visual Senses. Instituto Superior Técnico (2013). 